\title{
ORAL HEALTH AND AN AGEING POPULATION
}

Introduction

The world population which exceeds 6 billion at the moment is ageing. Major advances in the health care along with numerous social and economic factors have resulted in increased life expectancy. It is estimated that by $2050,25 \%$ of world population will be above the age of 60 years (1). Sri Lanka is also experiencing the same phenomenon. Due to these developments Dentists are bound to experience an increase percentage of elderly patients in their practices $(1,6)$.

Often the clinical presentations of these elderly patients differ from the others. Most of the time a person who is over the age of 60 will be suffering from at least one type of a chronic illness. The disease itself along with the medications taken may result in complications to the oral health (2).

Diseases such as Diabetes, Hypertension, Hyper cholestremia, Chronic Heart disease, Chronic Kidney disease, Arthritis, Osteoporosis ,Respiratory Diseases, Cancer, Mental disorders and Substance abuse are commonly encountered in the elderly (3). The treatment for almost all of the above mentioned conditions consists of number of medications which have to be taken over a long period of time. Another issue that is common among the elderly is injury due to falls which can lead to short term and long term health complications $(3,4)$.

Dentinal Caries (fig.1), Periodontal disease (fig.2), Tooth loss (fig.2) ,Xerostomia ,Burning mouth syndrome, Tooth wear (fig.3), Oral Cancer(fig.4), Denture related problems, Reduced masticatory efficiency, Compromised aesthetics and Complications due to failing dental treatment are dental problems commonly encountered in the elderly (5). The clinician should be mindful to the fact that the presentation of these problems will vary in severity and extensiveness compared to other patients.

There is a significant difference in the clinical presentation among the elderly population. Most of the time elderly have more than one condition present at the same time in the mouth. In addition to the severity of the presentation is higher due to the presence of medical complications as well as polypharmacy (5).

When a treatment plan is formulated for an elderly patient the following factors should be taken into consideration.

The socio economic variables should also be taken into consideration when treating the elderly. The clinician would be encountering a patient who has had ample experiences in dental treatments. $\mathrm{He} / \mathrm{she}$ would be well versed in the success and failures of certain treatment modalities. Sometimes he/she might be familiar with the nomenclature that we use as clinicians. Therefore, the clinician should be well versed in the prognosis of treatment options he/she has proposed and should also be willing to provide extensive information during the consultation (7).

\section{Dr. Sirimevan Bandara Samarakoon}

BDS, MD - Consultant in Restorative Dentistry

Teaching Hospital, Ratnapura 
It is important to consider the financial situation of the elderly patient as well. Some could be selfsupporting while others may be taken care of by their children or next of kin. This socio economic condition of the patient might prevent him/her receiving the optimal treatment (8).

The general medical condition of the patient might be not indicative for invasive treatments. The physician who is looking after the general health of the patient might indicate that the patient's physical/mental status is not suitable for the proposed treatment plan (8).

A life time of dental treatments would educate the patient regarding the limitations of the dental treatments as well as the ability of the clinician as well. This in turn would play a part in lowering or raising the expectations of the treatment out come as well. The quality of life that the patient is experiencing would also play a part in the final treatment outcome .The perception of the patient regarding how he/she should be living gets reflected on the treatment he/she seeks (8).

The factors that were discussed could be explained by the following example. An edentulous patient may seek treatment or be content with not having teeth. The patient who seeks treatment may want removable dentures or implant supported fixed bridges for both arches.

Sometimes there might be patients who seek more aesthetic outcomes. They might want to replace missing teeth, bleaching of teeth or cover exposed teeth surfaces. Patient's medical and mental health would determine whether a simple treatment plan with few visits or a complex treatment plan with number of visits is suitable for the him/her. It is prudent to consider the ability and motivation of the patient regarding the long term maintenance of the existing dentition as well as prosthesis.

In these circumstances it is important to consider all the factors when a treatment plan is designed. The clinician should have a detailed discussion with the patient. It is important to point out the advantages and dis advantages of all the possible treatment possibilities. The prognosis of the treatment methods and expected outcomes if it fails should be correctly informed. Sometimes the elderly patients are liable to seek legal redress if they are not properly informed of the outcomes (9).

It is of great importance that effective preventive treatment methods are incorporated into the treatment plan. The aim of the prevention programme should be properly explained therefore reducing the burden to the patient as well as to the clinician. Patient's ability to adapt and maintain the proposed treatment plan should be taken into consideration.

The clinical set up should be appropriately arranged to make the visit as comfortable as possible to the elderly patient. Priority parking, easy access to the clinic and chair, pharmacy and laboratory facilities, wheel chair access and educated and trained supporting staff are some of the examples (10).

\section{Conclusion}

The aging population is rapidly increasing and will make up a significant portion of the patients at the dental practices around the world. Most of them are experienced in dental treatments. Therefore they tend to have high expectations on the treatment outcome. Incorporation of more preventive treatments would ensure increased prognosis of the existing dentition as well as of the prosthesis. Empathy and sympathy should be concurrently dispensed during treatments. Improved quality of life for the seniors should be the ultimate goal of the Practitioners. 


\section{Clinical presentation of common oral problems in elderly}

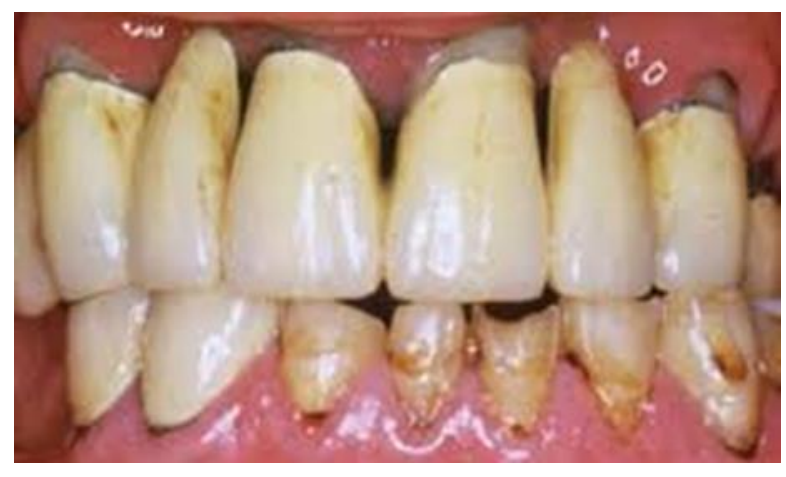

Fig.1: Root caries

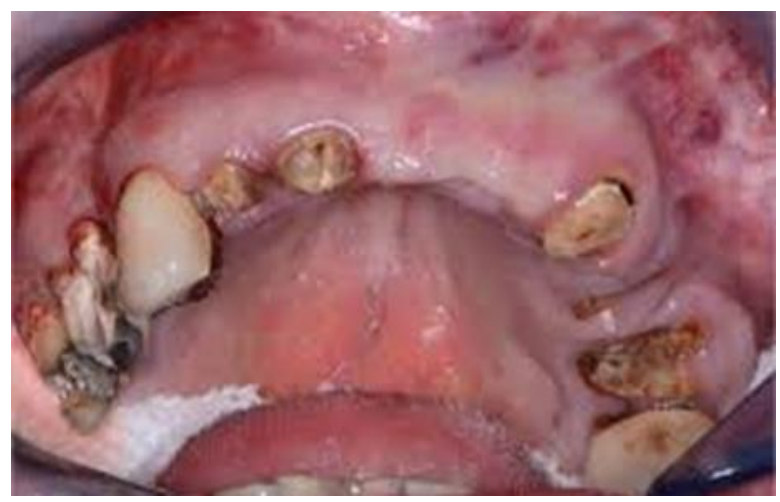

Fig 3: Tooth wear

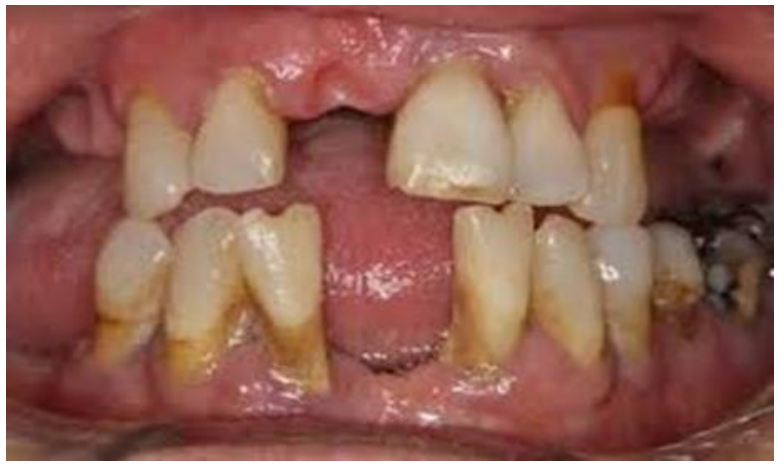

Fig.2: Periodontal disease

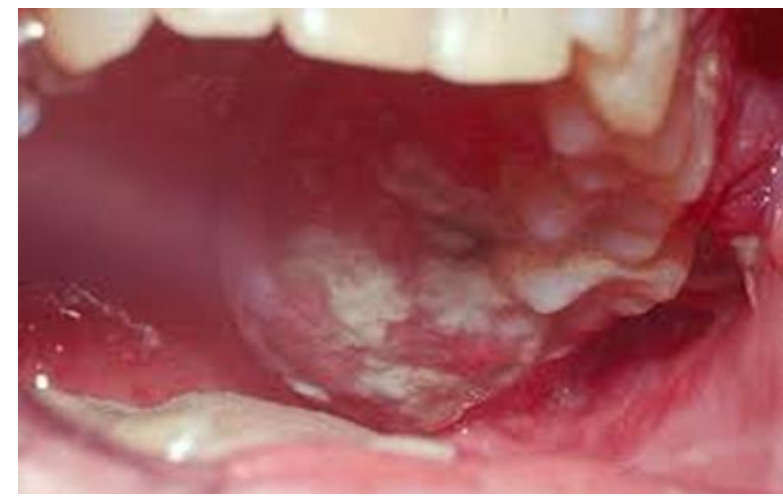

Fig 4 : Oral Cancer

\section{$\underline{\text { References }}$}

1. www.fdiworlddental.org/what-we-do/projects/oral-health-for-an-ageing-population

2.Müller F, Shimazaki Y, Kahabuka F, Schimmel M. Oral health for an ageing population: the importance of a natural dentition in older adults. Int Dent J. 2017 Sep; 67 Suppl 2:7-13.

3. Elisa M. Ghezzi , Kobayashi K, Deok-Young Park and Srisilapanan P. Oral healthcare systems for an ageing population: concepts and challenges. Int Dent J 2017 Sep; 67 Suppl 1: 26-33

4. William M, Thomson, Sun young Ma. An ageing population poses dental challenges. Sin Den J 2014; 35:3-8

5. Ronald LE. Oral Health and the Aging Population. J American Den Ass 2007 Sep; 138 Suppl 1:S5-S6

6. Ezeh AC, Bongaarts J, Mberu B. Global population trends and policy options. Lancet 2012; 380:142-148

7. Thomson W, Spencer AJ, Slade GD, Chalmers JM.Is medication a risk factor for dental caries among older people? Evidence from a longitudinal study in South Australia. Commun. Dent. Oral. Epidemiol.2002; 30: 224-232

8. Lauritano D, Moreo G, Della Vella, Di Stasio D, Carinci F, Lucchese A and Petruzzi M .Oral Health Status and Need for Oral Care in an Aging Population: A Systematic Review. Int. J. Environ. Res. Public Health. 2019; 16:1-23

9. Mary McNally M, Kenny N. Ethics in an Aging Society. Challenges for Oral Health Care. J Can Dent Assoc 1999; 65:623-6

10. Ettinger RL. The unique oral health needs of an aging population. Dental Clinics of North America 1997 Oct; 41(4):633-649 